\title{
Spatio-temporal Distribution Characteristics of the Cooperation Between Logistics Industry and Economy in Southwest China
}

\author{
Nengye $\mathrm{Mu}^{1,2,3,4} \cdot$ Yuanshun Wang ${ }^{1} \cdot$ Peiling Tian ${ }^{1}$
}

Received: 22 November 2021 / Accepted: 27 December 2021

(c) The Author(s) 2022

\begin{abstract}
The rapid development of logistics industry has become an important force to promote the improvement of regional competitiveness, but there has been little research on the evolution process and the distribution characteristics of the cooperation between logistics industry and economy from the perspective of qualitative and quantitative. Based on the evaluation index system, we analyzed the evolution process and the cooperation characteristics in Southwest China from three perspectives: regional evolution process, urban development characteristics and urban co-evolution analysis. The research results show that: (1) the synergy degree between the logistics industry and the economy in the whole southwest region experienced a process of falling first and then rising from 2011 to 2019, and finally reached the stage of reluctance coordination. (2) The urban logistics industry in Southwest China showed a polar-core development phenomenon, while the urban economy presented a spatial pattern of urban agglomeration development. (3) There were spatial distribution differences in the evolutionary trajectories of urban logistics industry and urban economy. (4) The urban synergy degree was getting better in the evolution process and showed regional differences and spatial dependence in spatial distribution. Our findings can help guide urban planners in formulating the development plans for logistics industry and economy.
\end{abstract}

Keywords Logistics industry $\cdot$ Economy $\cdot$ Synergy degree $\cdot$ Spatial difference $\cdot$ Spatio-temporal distribution characteristics

\section{Introduction}

Logistics industry has become the fundamental, strategic and leading industry of national economy development [1-4], and it is closely related to economic growth. There have been many research results on the single aspect

Nengye $\mathrm{Mu}$

nengyemu@163.com

Yuanshun Wang

yuanshunwang@126.com

Peiling Tian

xttian37@163.com

1 School of Transportation and Logistics, Southwest Jiaotong University, Chengdu 611756, Sichuan, China

2 National and Local Joint Engineering Laboratory for Intelligent Integrated Transportation, Chengdu 611756, Sichuan, China

3 National Engineering Laboratory of Integrated Transportation Big Data Application Technology, Chengdu 611756, Sichuan, China

4 Xinjiang University, Urumqi 830046, China of logistics industry development or economic improvement. The research on logistics industry mainly started with total amount of logistics, regional layout and so on, which proposed relevant countermeasures such as integrating resources and supporting enterprises based on analyzing the current situation of logistics development [5]. With the increasingly close relationship between logistics industry and economy, scholars have gradually shifted research directions to study the relationship between the development level of them.

Previous studies have explored the close relationship between logistics industry and economy from the perspective of correlation. First of all, scholars have found that transportation networks and logistics facilities have made an impact on economic progress. It was shown by Zhang [6] that transportation facilities such as transportation networks and trucks were closely related to economic development, and the transportation played an important role in economic growth. Sainz et al. [7] pointed out the impact of Zaragoza logistics platform and transportation facilities on regional economic development through data analysis. Second, some scholars have studied the relationship between 
the development of logistics industry and economy through mathematical models. The econometric models were used to prove that regional economic growth would lead to an increase of logistics demand, thereby promoting the development of logistics industry [8]. Jie [9] evaluated the logistics industry development in China and the contribution rate of various components of logistics industry to economic growth through the data-driven model. Gu, and Zhou [10] discussed the main economic factors affecting the development of logistics in Guangxi from 2001 to 2016 based on the gray correlation analysis. By establishing the logistics industry agglomeration development model, Sun [11] found that there was a nonlinear cooperative symbiosis relationship between the logistics industry agglomeration and the regional economic development in China.

In addition, the coupling coordination model has been applied to analyze the relationship between logistics industry and economy. Hu [12] studied the coupling degree development between the logistics industry and the regional economy in Hunan by establishing a gray correlation coupling model. It was found that the coupling degree between the logistics industry and the regional economy in the central region of Jiangxi was not high, but the synergy degree was high [13]. Xie, and Zhang [14] found that the integrative development of the logistics and the regional economy in Beijing, Tianjin and Fujian showed phased characteristics from 2005 to 2019, changing from "imbalance" to "harmonization". To sum up, the academic research on the relationship between logistics industry and economy have produced many conclusions and achievements. However, few studies systematically analyze the synergy evolution process of logistics industry and economy and the spatio-temporal distribution characteristics between them from the perspective of qualitative and quantitative, as well as the correlation between synergy degree changes and internal factors.

This case studied the development of logistics industry and economy and the cooperation between them in Southwest China. Southwest China is an important part of the New Western Land-Sea Corridor and a cooperation area of China-Singapore Strategic Connectivity Demonstration Project. In addition, it is composed of Chongqing municipality and the four provinces of Sichuan, Yunnan, Guizhou, and Guizhou (Fig. 1). Therefore, the research of this paper has certain guiding significance for realizing regional coordinated development.

In this study, we confirmed the method for measuring the development level of logistics industry and economy by establishing the evaluation index system and the way to calculate the urban synergy degree between them through the coupling degree model first. Then we analyzed the evolution process and the cooperation characteristics in the whole southwest region and its 61 cities from three perspectives: the regional evolution process in the whole southwest region, the urban development characteristics of logistics industry and economy, and the urban co-evolution analysis between logistics industry and economy. A combination of qualitative and quantitative method was used to analyze the spatio-temporal distribution characteristics of the urban synergy degree between logistics industry and economy in urban co-evolution. Finally, we put forward conclusions and suggestions for urban development based on the research results.

Fig. 1 Study area

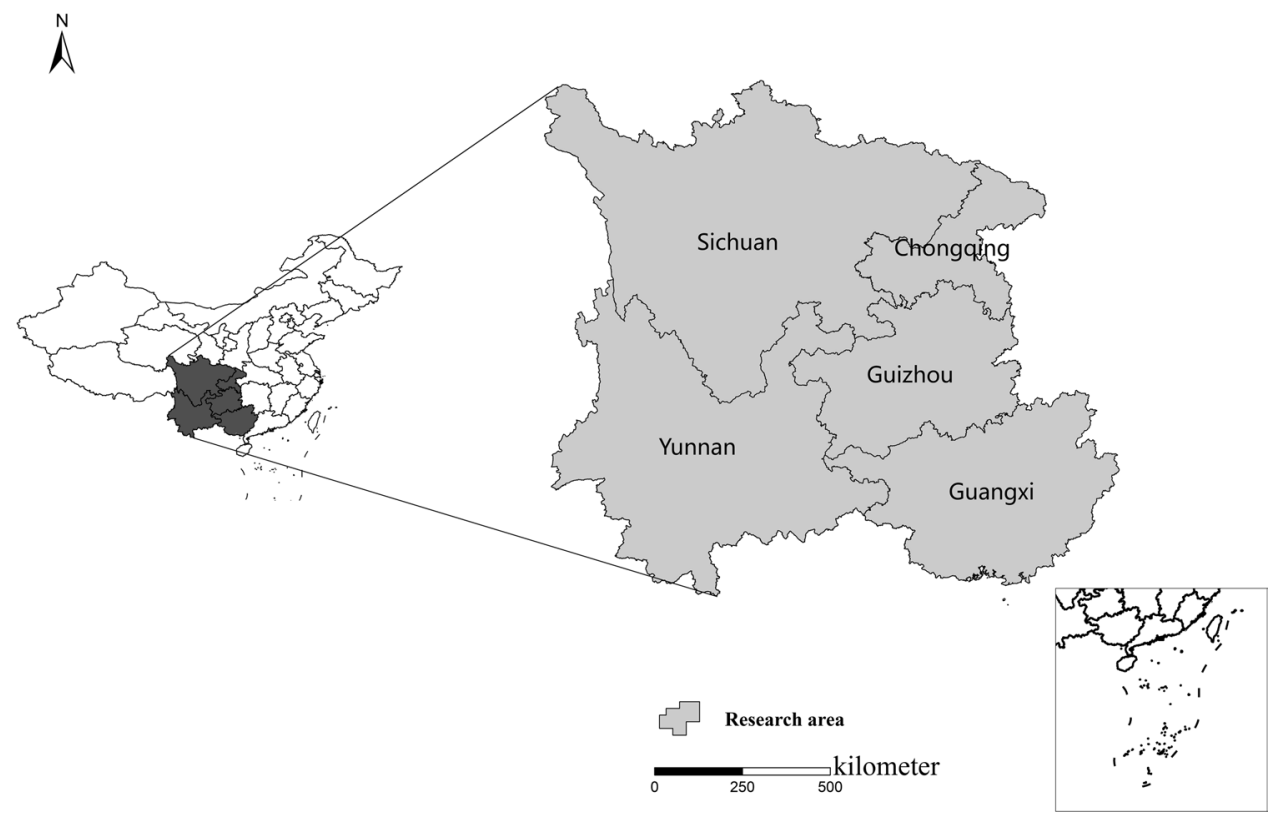




\section{Data Sources and Research Methods}

\subsection{Data Sources}

To analyze the development level of logistics industry and economy and the cooperation changes between them in Southwest China, this paper selected panel data from 2011 to 2019 as the research sample. The panel data was directly or indirectly derived from National Statistical Yearbook, Urban Statistical Yearbook, City Statistics Bureau, City Post Administration, etc.

\subsection{Research Methods}

\subsubsection{Development Calculation of Logistics Industry and Economy}

The evaluation index system should comprehensively reflect the development status of the research objects from different perspectives and multiple directions [15-18]. We considered that the logistics industry development was related to four aspects of infrastructure, development scale, development potential and demand potential, and the economic development was related to four aspects of economic aggregate, economic structure, economic development potential and economic benefits. Therefore, we constructed the secondary index system for calculating the development level of logistics industry and economy (Table 1). This section used the range standardization method to standardize the panel data and applied the improved entropy weight method to evaluate the weight of 24 indicators. After calculating the evaluation value of the first-level index by the entropy method and the real value of the second-level index, the improved entropy weight method used the evaluation value of first-level index and the entropy method to assess the development level of logistics industry and economy again $[19,22]$.

\subsubsection{Evolution Analysis on Logistics Industry and Economy}

The spatial center of gravity can characterize the overall distribution of regional elements, and the migration law of element center of gravity represented the overall dynamic evolution process $[20,21]$. This method was also used by Shobugawa et al. [23] to construct a WSD model to study the spread of influenza epidemics. This article calculated the geometric centers of gravity of each administrative unit in

Table 1 Evaluation index system of logistics industry and economy

\begin{tabular}{|c|c|c|c|}
\hline Target layer & First-level index & Second-level index & Unit \\
\hline \multirow[t]{12}{*}{ Logistics Industry } & \multirow[t]{4}{*}{ Infrastructure } & Highway traffic mileage & $\mathrm{Km}$ \\
\hline & & Railway operating mileage & $\mathrm{Km}$ \\
\hline & & Postal service outlets & Number \\
\hline & & Fixed asset investment in transportation, storage and postal industry & 100 million Yuan \\
\hline & \multirow[t]{3}{*}{ Development scale } & Freight volume & 100 million tons \\
\hline & & Business volume of post and telecommunications & 100 million Yuan \\
\hline & & Express business volume & 100 million pieces \\
\hline & \multirow[t]{3}{*}{ Development potential } & Growth rate of freight volume & $\%$ \\
\hline & & Growth rate of total post and telecommunications business & $\%$ \\
\hline & & Growth rate of express business volume & $\%$ \\
\hline & \multirow[t]{2}{*}{ Demand potential } & Number of students in colleges and universities & 10,000 people \\
\hline & & Mobile internet users & 10,000 households \\
\hline \multirow[t]{12}{*}{ Economy } & \multirow[t]{4}{*}{ Economic aggregate } & GDP & 100 million Yuan \\
\hline & & Total retail sales of social consumer goods & 100 million Yuan \\
\hline & & Total import and export volume & US\$ 100 million \\
\hline & & Total investment in fixed assets & 100 million Yuan \\
\hline & \multirow[t]{3}{*}{ Economic structure } & Added value of primary industry & 100 million Yuan \\
\hline & & Added value of secondary industry & 100 million Yuan \\
\hline & & Added value of tertiary industry & 100 million Yuan \\
\hline & \multirow[t]{3}{*}{ Development potential } & GDP growth rate & $\%$ \\
\hline & & Growth rate of fixed asset investment & $\%$ \\
\hline & & Growth rate of total retail sales of social consumer goods & $\%$ \\
\hline & \multirow[t]{2}{*}{ Economic benefits } & Per capita GDP & Yuan \\
\hline & & Per capita disposable income & Yuan \\
\hline
\end{tabular}


the southwestern region, and the weighted centers of gravity of logistics industry development level and economy development level. The closer the two centers of gravity were, the higher the synergy degree of their spatial distribution [24, 25]. As formulated below

$\bar{X}=\frac{\sum_{i=1}^{n} W_{i} X_{i}}{\sum_{i=1}^{n} W_{i}}$

$\bar{Y}=\frac{\sum_{i=1}^{n} W_{i} Y_{i}}{\sum_{i=1}^{n} W_{i}}$

where $\bar{X}$ and $\bar{Y}$ represent the longitude and latitude of the element center of gravity, respectively. $X_{i}$ and $Y_{i}$ represent the longitude and latitude of the subdomain center of gravity, respectively, and $n$ is the number of subdomains. $W_{i}$ denotes the coefficient value of subdomain feature, and it is the development level of urban logistics industry or urban economy in this study.

\subsubsection{Cooperation Measurement Between Logistics Industry and Economy}

By comparing various synergy degree measurement models, we selected the coupling degree model to calculate the synergy degree between logistics industry and economy. Coupling degree is mainly to depict the interaction degree between logistics industry and economy, which is denoted as $C$. Synergy degree is used to describe the coordination degree between logistics industry and economy, describing the process of harmonious unification between the two over time, which is denoted as $S(t)$. The synergy degree was divided into nine level intervals (Table 2). As formulated below [19]

$$
\begin{aligned}
& C=2 \times \sqrt{\left(h_{x}(t) \times h_{y}(t)\right) /\left(h_{x}(t)+h_{y}(t)\right)^{2}}, \\
& S(t)=\sqrt{C \times \lambda}, \\
& \lambda=\alpha h_{x}(t)+\beta h_{y}(t),
\end{aligned}
$$

where $h_{x}(t)$ and $h_{y}(t)$ refer to the development level of the logistics industry and the economy in year $t$, respectively, and $\lambda$ is the contribution degree of logistics industry and economy to the growth of synergy degree. $\alpha$ and $\beta$ are the factors to be determined, representing the contribution coefficient of logistics industry and economy, respectively. Here, $\alpha=0.4$ and $\beta=0.6$.

\subsubsection{Spatial Autocorrelation Test}

Spatial autocorrelation test was used here to study the spatial dependence phenomenon of the urban synergy degree between the logistics industry and the economy in 61 cities. The Moran's I is valued from -1 to 1 , and if its absolute value tends to 1 , the correlation will be stronger. When the Moran's $I$ value is bigger than 0 , it indicates a positive correlation, otherwise it indicates a negative correlation. The formula for calculating the Moran's $I$ is as follows:

Moran's $I=\frac{n \sum_{i=1}^{n} \sum_{j=1}^{n} s_{i j}\left(S_{i}-\bar{S}\right)\left(S_{j}-\bar{S}\right)}{\sum_{i=1}^{n} \sum_{j=1}^{n} s_{i j} \sum_{i=1}^{n}\left(S_{i}-\bar{S}\right)^{2}}$.

In the formula, $n$ is the number of cities, and $s_{i j}$ refers to the spatial weight matrix. $S_{i}$ and $S_{j}$ denote the synergy degree between the logistics industry and the economy of city $i$ and city $j$, respectively.

\section{Research Results}

\subsection{Regional Evolution Process Analysis in Southwest China}

This section measured the development level of logistics industry and economy and the synergy degree between them in the whole southwest region by obtaining panel data from 2011 to 2019. According to the results (Fig. 2), the synergy degree in the whole southwest region went through a process of falling first and then rising from 2011 to 2019. Finally, it was raised to 0.4480 in 2019 , which was at the stage of reluctance coordination. It is worth noting that the development level of logistics industry and economy also went through the process of first declining and then rising, but the former changed relatively faster than the latter. Among them, the logistics industry development level declined significantly from 2011 to 2012, then increased slowly from 2013
Table 2 Synergy degree interval division and level

\begin{tabular}{llclll}
\hline Interval & Level & Interval & Level & Interval & Level \\
\hline$[0.0,0.1)$ & High disorder & {$[0.3,0.4)$} & Endangered disorder & {$[0.7,0.8)$} & General coordination \\
{$[0.1,0.2)$} & Moderate disorder & {$[0.4,0.6)$} & Reluctance coordination & {$[0.8,0.9)$} & Good coordination \\
{$[0.2,0.3)$} & Low disorder & {$[0.6,0.7)$} & Primary coordination & {$[0.9,1.0]$} & Wonderful coordination \\
\hline
\end{tabular}


Fig. 2 Development level of logistics industry and economy and the synergy degree in Southwest China

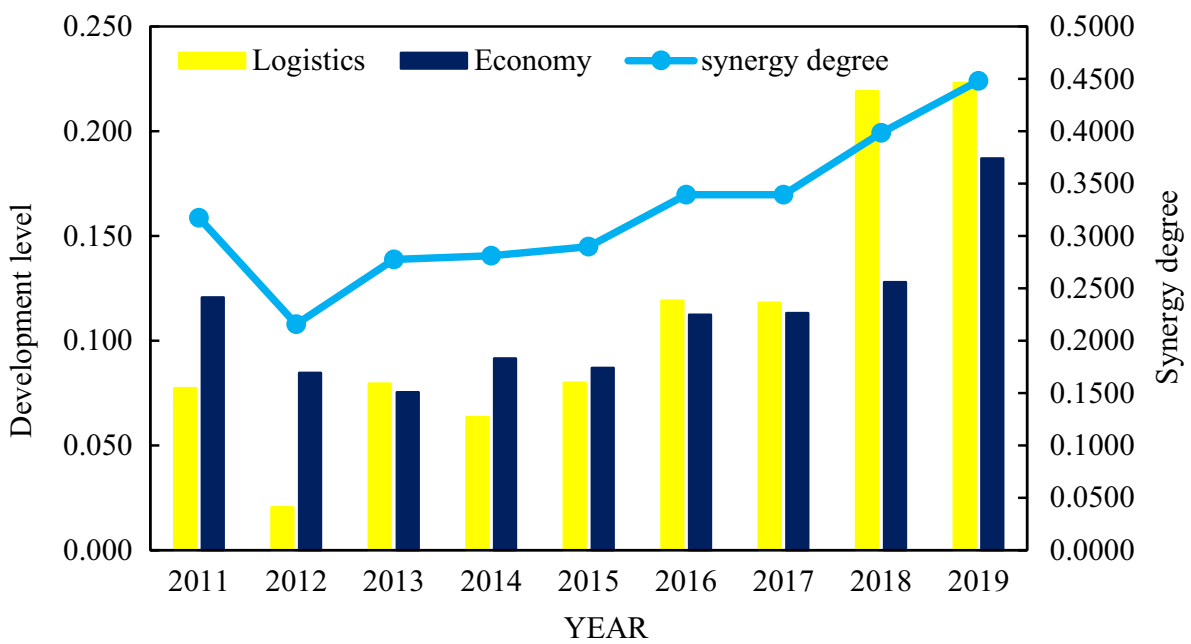

to 2017 , and eventually achieved a growth of 1.88 times in 2019. At the same time, the economic development level stopped declining in 2013 and grew by 0.55 times in 2019 .

These changes are closely related to the proposal and implementation of a series of measures. First, 2016-2020 is the period of China's "13th Five-Year Plan" and a critical period for building a moderately prosperous society comprehensively. In addition, the development of logistics industry and economy of most cities in Southwest China is slightly behind the national average development level. In the context, the government proposed policies to support the sustainable development of industry and economy in Southwest China. In 2017, the government and market jointly promoted the rapid development of e-commerce industry and played an important role in strengthening digital economy and helping rural revitalization, which became a new driving force for economic growth. Then, China and Singapore formally signed an agreement to create the New Western Land-Sea Corridor between West China and Singapore in 2018, bringing significant benefits to the infrastructure construction and operation of southwest channel [26]. In addition, the Belt and Road Initiative stimulated the development potential of West China, which resulted in a rapid upward trend in economic development and attracted more attention from global capital and advanced technology [27].

\subsection{Urban Development Characteristics of Logistics Industry and Economy}

We examined the urban development level of logistics industry and economy in Southwest China in 2015, 2017 and 2019. As shown in Fig. 3, the urban logistics industry presented a phenomenon of polar-core development. As the core cities of logistics industry, Chongqing, Chengdu, Kunming, Guiyang, and Nanning had a high development level, while the other cities generally fell behind. However, the development level of Nanning's logistics industry declined in 2019, while Zunyi's improved significantly and exceeded Nanning's. Relying on the municipality Chongqing and provincial capital cities, the urban economy in Southwest China

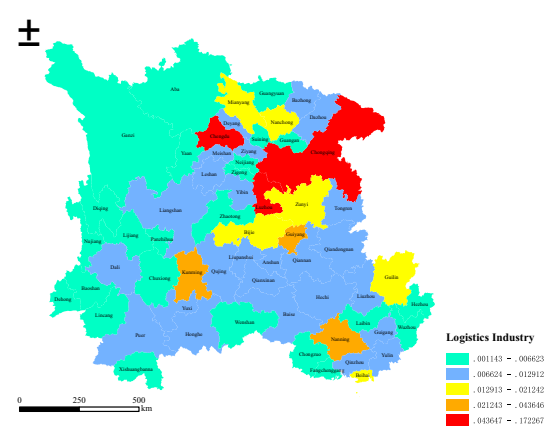

(a) 2015

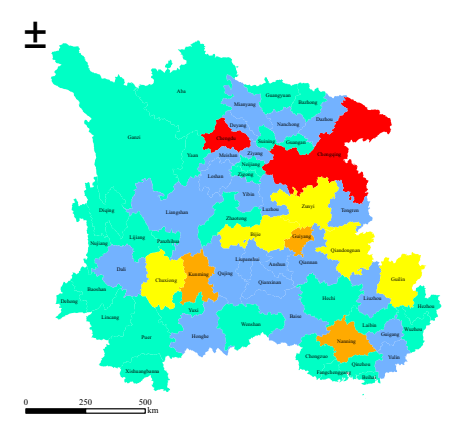

(b) 2017

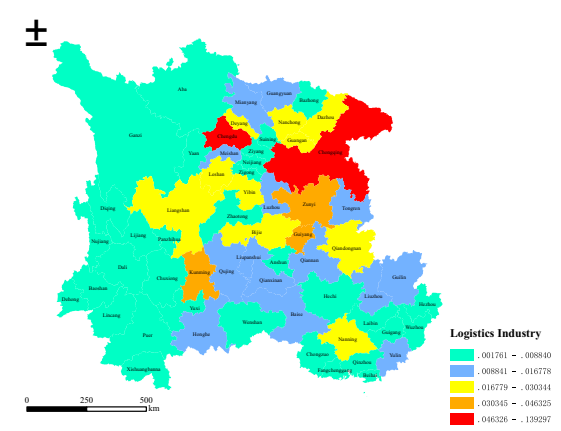

(c) 2019

Fig. 3 Spatial distribution of urban logistics industry development level 
presented a spatial model of urban agglomeration development in Fig. 4, which was most obvious in 2017. It gradually formed four city agglomerations in 2019 , such as the urban cluster of Chengdu, Deyang, and Mianyang, the urban cluster of Chongqing, Zunyi, and Guiyang, the urban cluster of Kunming, Qujing, Yuxi, and Honghe, and the urban cluster of Nanning, Chongzuo, and Fangchenggang.

Chongqing as a municipality, and Chengdu, Kunming, Guiyang and Nanning as the provincial capitals, have natural location advantages, more population and economic aggregate and better traffic conditions. Therefore, these five cities concentrate various favorable resources so that their development level of logistics industry and economy is excellent compared with the surrounding small cities. The average total proportion of the logistics industry development level in these five cities was as high as $39.8 \%$ in Southwest China from 2015 to 2019, and the average economic development level had a proportion of $39.6 \%$. As time goes by, the development of logistics industry and economy in Southwest China emerged different distribution types. In 2015, the logistics industry and the economy showed a typical shape of "Pyramid", which means that cities with better development status occupied a minority. In 2017, the logistics industry development level was extremely unbalanced, and the economic development level showed spillover effects. In 2019 , there were east-west differences of logistics industry and economy in spatial layout. It is worth noting that the overall development of logistics industry and economy in western cities of Southwest China showed an unfavorable trend due to the particularity of geographical conditions.

\subsection{Urban Co-evolution Analysis Between Logistics Industry and Economy}

\subsubsection{Evolutionary Trajectory of the Space Center of Gravity}

The spatial center of gravity of the logistics industry and the economy in Southwest China was in the northeast of geometric center of gravity, reflecting that there was certain synergy in spatial distribution between them from 2015 to 2019 (Fig. 5). Although the evolutionary trajectories were intersecting, there were still differences in spatial distribution. First, it was different in the evolutionary direction. The spatial center of gravity of logistics industry shifted slightly to the northwest, but the economic spatial center shifted to the southwest. Second, the stability difference was obvious. The economic spatial center of gravity experienced significant position offset as opposed to the logistics industry.

The misalignment of the two spatial centers of gravity can be attributed to regional differences in the north-south direction. (1) Compared with Yunnan, Guizhou and Guangxi, Sichuan and Chongqing are developing relatively faster and more developed in logistics industry. In addition, Chengdu is an international comprehensive transportation hub and an important national center of economy, science and technology, finance, culture and innovation, and external communication, which can drive the progress of the logistics and the economy in Sichuan. As the international gateway hub and the international communication center in the central and western regions, Chongqing can conduct more trade exchanges with domestic and foreign cities. These are the reasons why the economic spatial center of gravity started in the northeast of Southwest China in 2015. (2) Sichuan and Chongqing will attract more logistics enterprises to settle in owing to their larger population density, better economic development level and better logistics infrastructure conditions. Consequently, the spatial center of gravity of logistics industry shifted slightly to the northwest. (3) With the implementation of the rural revitalization strategy and agricultural supply-side reform, Guizhou, Yunnan and Guangxi are getting better with the support of the state. The healthily economic development through vigorously developing tourism, livestreaming to help farmers and other means in these three provinces is an important reason for the southwest shift of the economic center of gravity from 2015 to 2019 .

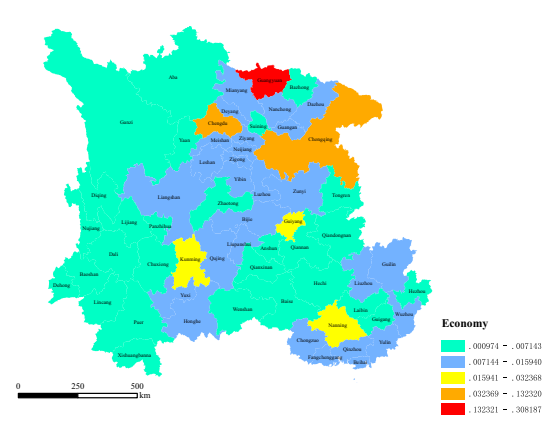

(a) 2015

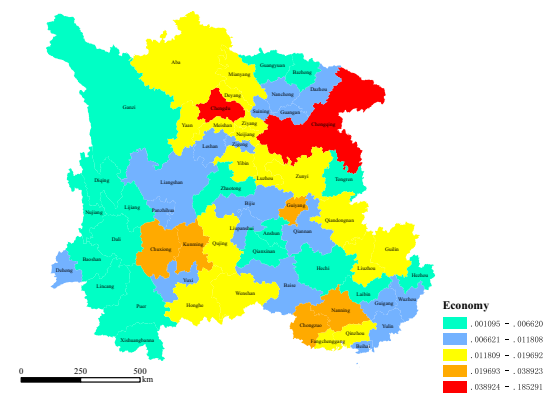

(b) 2017

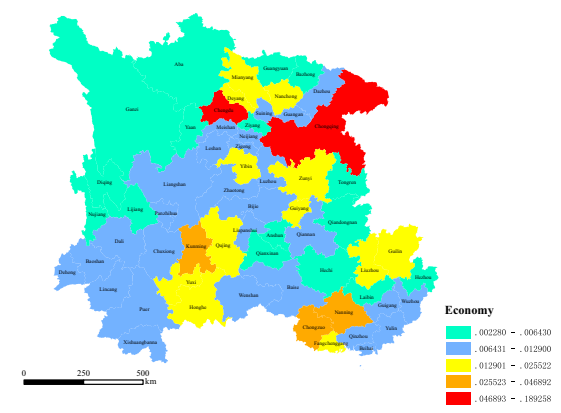

(c) 2019

Fig. 4 Spatial distribution of urban economic development level 


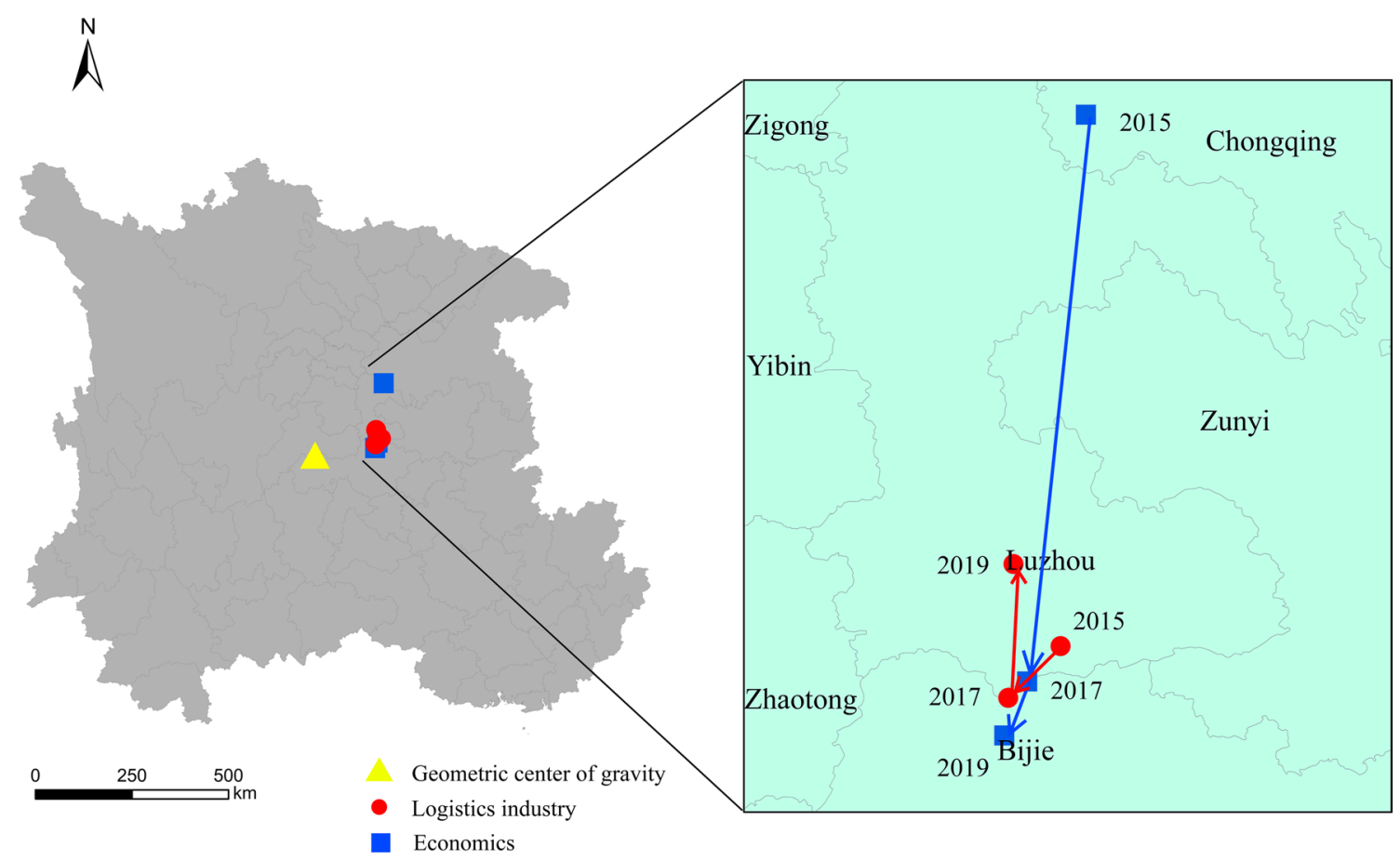

Fig. 5 Evolutionary trajectory of the spatial center of gravity of the logistics industry and the economy in Southwest China

\subsubsection{Spatio-temporal Distribution Characteristics of Urban Synergy Degree}

The synergy degree between logistics industry and economy indicates the degree of coordination between the two in space. The urban synergy degree in Southwest China was showing an increasing trend in the evolution process, and the spatial distribution was characterized by a pattern of "low in the west, high in the northeast and uneven distribution in central and south" in 2015, 2017 and 2018 (Fig. 6).

In the process of evolution, the synergistic relationship between urban logistics industry and urban economy was getting better. In 2015, the urban synergy degree in Chongqing and Chengdu was the best among all cities, which was at the stage of endangered disorder. In addition, the urban synergy degree in Guangyuan was at the low disorder stage, and Kunming, Luzhou, Nanning, Guiyang and other cities were at the moderate disorder stage, and $60.56 \%$ of cities were at the stage of high disorder. Then, the synergy degree level in Chongqing and other five core cities was increasingly prominent in 2017. However, the city with the fastest increase in synergy degree was Chuxiong, followed by Chengdu, Chongqing. In addition, about $88.52 \%$ of cities achieved significant improvement in the urban synergy degree during the two years. For example, the urban synergy degree levels in Qiandongnan, Chongzuo, Neijiang, and Ziyang have risen from high disorder to moderate disorder, indicating that the synergic relationship between logistics industry and economy was effectively improved. According to calculation, Chongqing, Chengdu, Kunming, Nanning and Guiyang were the top five cities in terms of urban synergy degree in 2019 . The urban synergy degree

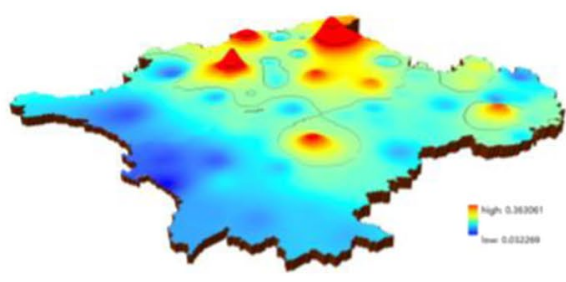

(a) 2015

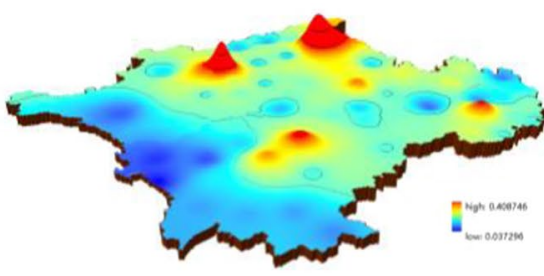

(b) 2017

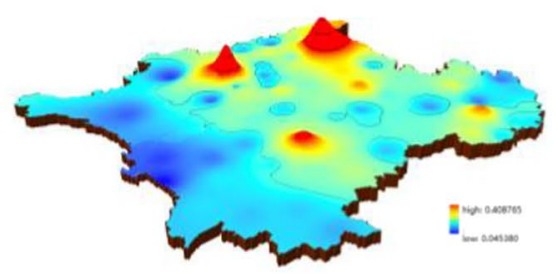

(c) 2019

Fig. 6 Spatial distribution of the urban synergy degree in Southwest China 
in Chengdu, Chongqing and surrounding cities has made great growth during this period due to the proposal of the Chengdu-Chongqing urban agglomeration in 2018. The construction of the Chengdu-Chongqing urban agglomeration will promote urban cooperation and resources sharing and guide the common progress of logistics industry and economy in the surrounding cities. From 2015 to 2019, the number of high disorder cities fell by $13.11 \%$, which shows that urban infrastructure network construction, logistics industry and economy have made great progress under the stimulus of China's development plans, such as "Long-Term Plan for the Development of Logistics Industry (2014-2020)" and "Action Plan for promoting the construction of Logistics Channels (2016-2020)" [1, 28]. Besides, there was a slight downward trend in the synergy degree between in a few cities, which may be related to the inharmony between the development of logistics industry and economy. The main performance was that one was high but the other was low, or one improved obviously and the other showed a downward trend (Figs. 2 and 3).

In spatial distribution, the urban current development status and location conditions are diverse, so there are different spatial distribution characteristics of urban synergy degree in different provinces. Because Chengdu, Kunming, Guiyang, and Nanning are the capital cities of Sichuan, Yunnan, Guizhou, and Guangxi, respectively, their synergy degree was significantly higher than other cities in provinces (Fig. 7). The urban synergy degree in Sichuan was roughly represented by a distribution shaped like a tilted "F" (Fig. 7a-c). The urban synergy degree in Yunnan was shown as the "Core Radiation" distribution (Fig. 7d-f). The urban synergy degree in Guizhou was represented as the "Oblique Axis" distribution (Fig. 7g-i). The urban synergy degree in Guangxi was shown represented by the distribution of "Opposite Angles" (Fig. 7j-1).

On the one hand, some cities might emerge tourism industry and other pillar industries owing to environmental resources, resulting in the urban economic development obviously was better than the urban logistics industry, and it was also an important reason for the mismatched development between logistics industry and economy. Besides, the economic development level in some cities was slow to improve and the logistics infrastructure construction and industrial development were hindered by special geographical conditions, so that the urban synergy degree in these cities was at a low level. On the other hand, the core cities can attract global capital and advanced technology, which were the keys to driving progress of those cities in urban agglomeration area [29]. This radiation-driven effect came from the spillover effect of logistics industry and economy in core cities. We took Liupanshui as an analysis example here (Fig. 7g-i). The economic development level of it was lower than the local development level of logistics industry and the average urban economic development level in Guizhou. There are two reasons for this situation: the first is that the total economic volume and the economic development potential of Liupanshui were at a disadvantage in Guizhou. Second, as this city is an important railway hub city and one of the logistics distribution centers in Southwest China, the development level of the logistics industry was higher than the economy. Therefore, the development of the logistics industry and the economy was mismatched in this city.

\subsubsection{Spatial Autocorrelation Test}

To further explore the intrinsic relationship of the coordination between logistics industry and economy, this section used Arcgis10.6 to conduct a spatial autocorrelation test on the development level of urban logistics industry and urban economy and the synergy degree between them in Southwest China in 2019. The results show that the urban logistics industry and the synergy degree showed spatial self-correlation across the whole region, while the spatial distribution of urban economy was not different from the random pattern. The logistics industry had the highest $z$ score of 3.1548, which was higher than the critical value of 2.58 when the significance level of the standard normal distribution was 0.01 . The highest $z$ score of the urban synergy degree was 1.6935, which was higher than the critical value 1.65 when the standard normal distribution was at a significance level of 0.10 . Figure 8 shows the Moran' $I$ of the urban logistics industry and the synergy degree in 2019. It can be found that the $z$ score of the urban synergy degree was smaller than that of the logistics industry owing to the influence of the economic random pattern distribution. The spatial dependence of the urban synergy degree was affected by the combined action of logistics industry and economy, and mainly came from the location stickiness of core cities. At the same time, it was influenced by the logistics industry to a greater extent compared with the economy, which is tightly linked to the fundamental, strategic and leading nature of logistics industry.

\section{Conclusions and Discussion}

\subsection{Conclusion}

Based on the panel data in Southwest China from 2011 to 2019, we confirmed the method for measuring the development level of logistics industry and economy by establishing the evaluation index system and the means to calculate the urban synergy degree between them through the coupling degree model. Then, we analyzed the evolution process in the whole southwest region, the urban development characteristics of logistics industry and economy, and 


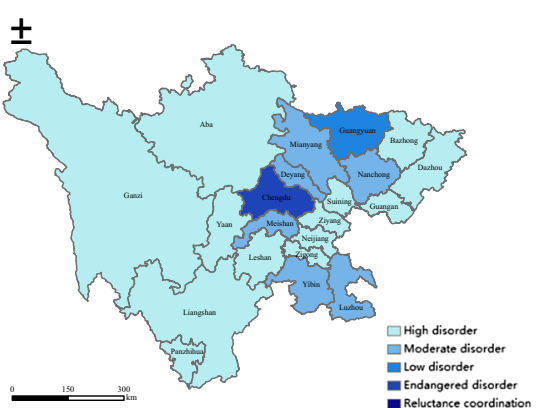

(a)

$\pm$

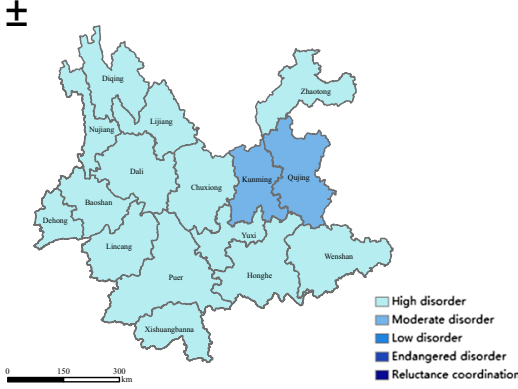

(d)

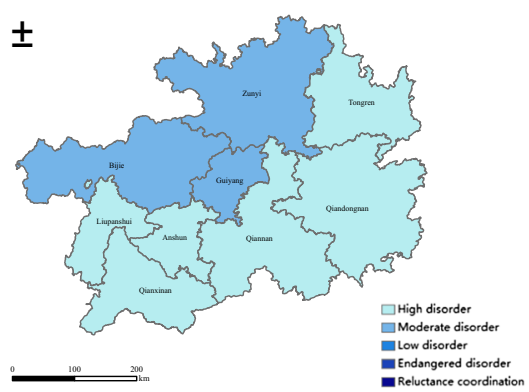

(g)

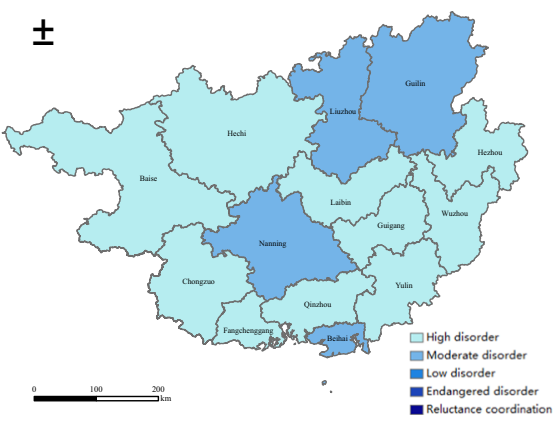

(j)

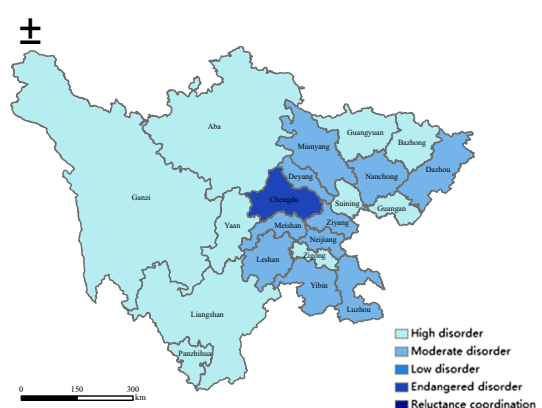

(b)

$\pm$

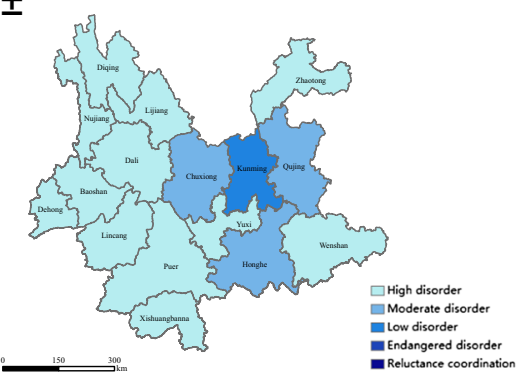

(e)

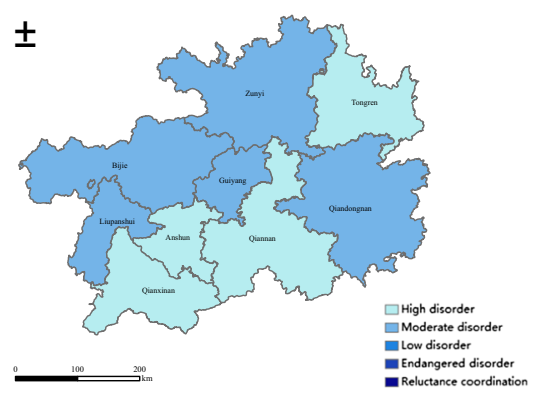

(h)

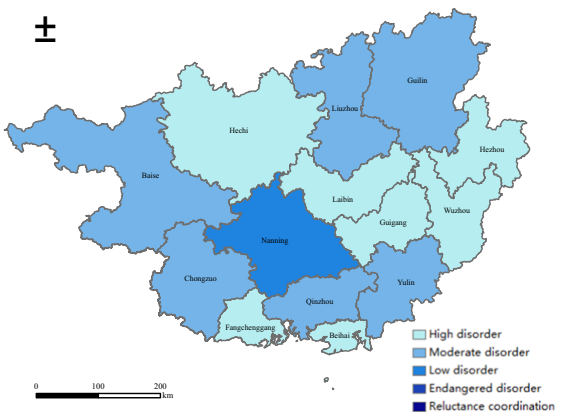

(k)

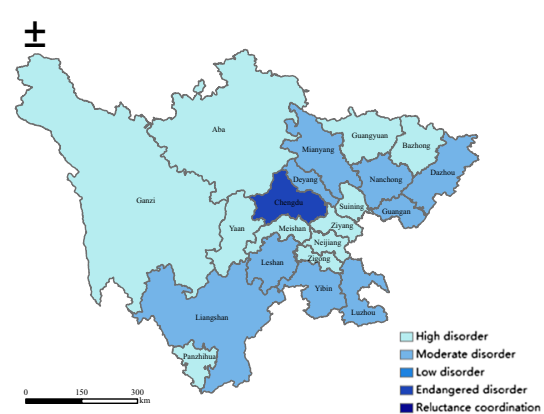

(c)

$\pm$

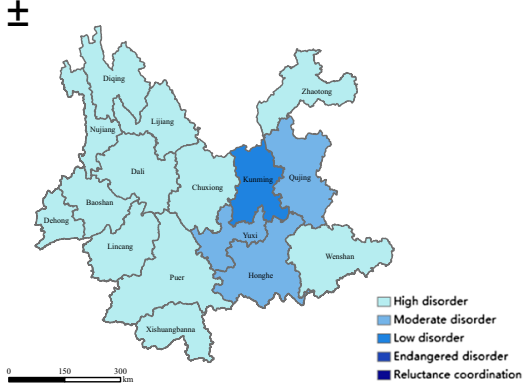

(f)

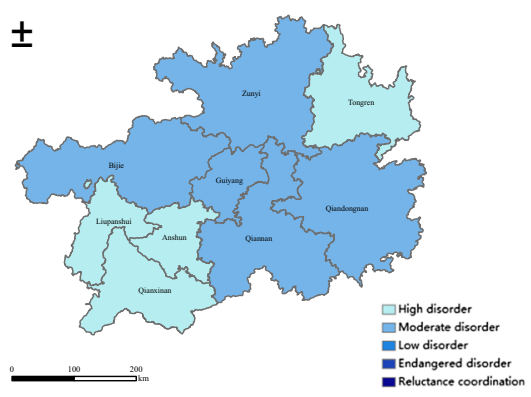

(i)

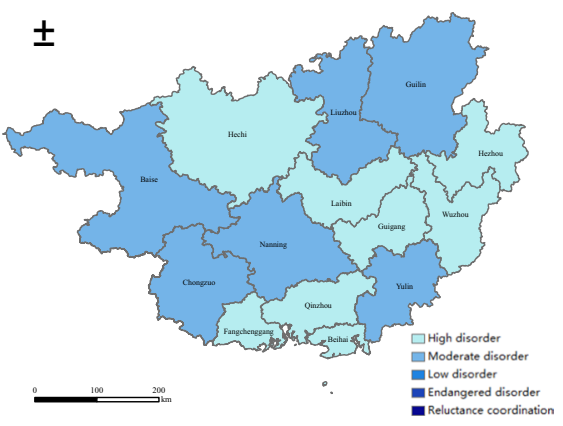

(I)

Fig. 7 Spatial distribution of the urban synergy degree in four provinces in 2015, 2017 and 2019

the cooperation evolution characteristics between logistics industry and economy in 61 cities. From this research, we draw four conclusions.
First of all, the synergy degree between the logistics industry and the economy in the whole southwest region experienced a process of falling first and then rising from 


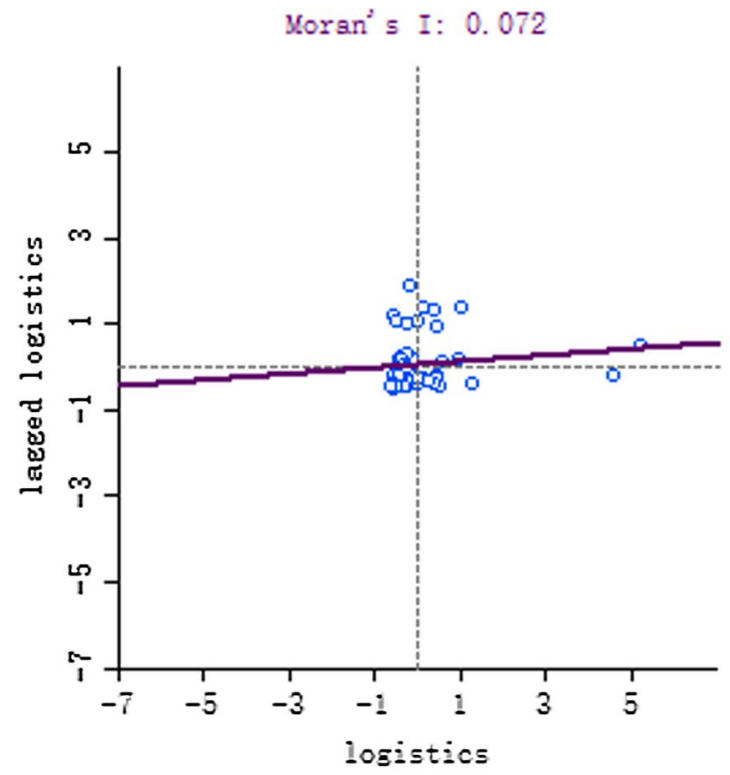

(a)

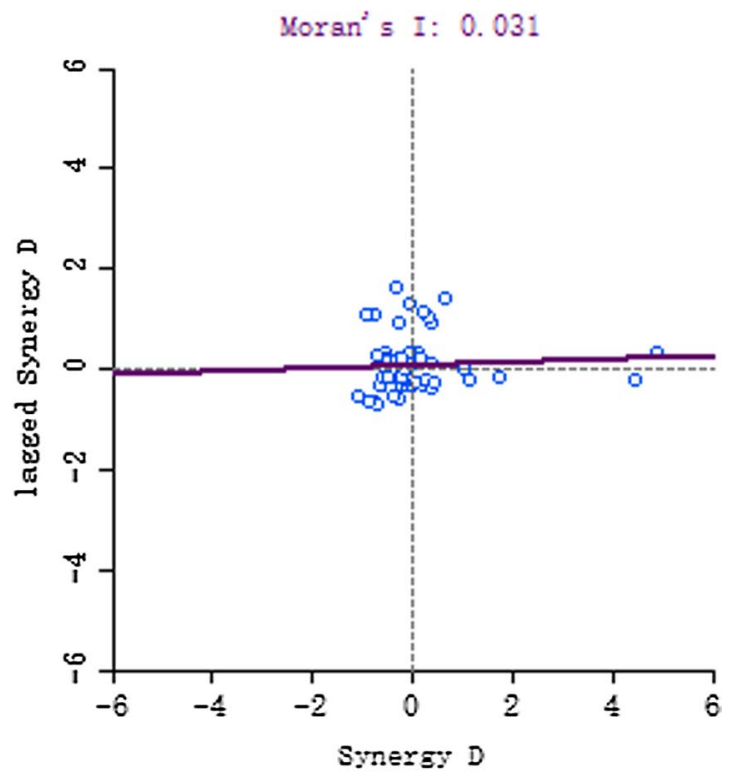

(b)

Fig. 8 Moran' $I$ of the urban logistics industry and the urban synergy degree

2011 to 2019, and was finally at a stage of reluctance coordination. Besides, the development level of logistics industry and economy also went through this process, but the pace of change was not consistent. Second, the urban logistics industry in Southwest China presented a polar-core development phenomenon, while the urban economy revealed a spatial type of urban agglomeration development in 2015, 2017 and 2019. Relying on location advantages, the municipality Chongqing and provincial capital cities concentrated various favorable resources for the industrial and economic development, and formed four urban agglomerations with Chongqing, Chengdu, Kunming, and Nanning as the core cities. Thirdly, there were spatial distribution differences between the evolutionary trajectories of the logistics industry and the economy in Southwest China from 2015 to 2019. The spatial center of gravity of logistics industry was relatively stable, but the economic spatial center of gravity shifted significantly to the southwest. Finally, the urban synergy degree between logistics industry and economy was getting better in the course of evolution. In the spatial distribution of 2015, 2017 and 2019, it showed a pattern of "low in the west, high in the northeast, and uneven distribution in the central and southern regions", and there were regional differences and spatial dependence. The urban synergy degree in Sichuan was roughly represented by the tilted " $F$ " distribution. In addition, Yunnan, Guizhou, and Guangxi, respectively, showed the "Core Radiation" distribution, the "Oblique Axis" distribution, and the "Opposite Angles" distribution. It is worth noting that the spatial dependence of urban synergy degree was affected by the joint effect of logistics industry and economy, which mainly come from the location stickiness of core cities.

Regarding the current situation and problems found in this article, we propose three suggestions. (1) Seize the development opportunity of policy support. Although the output value of logistics industry and economy has increased over time, it is still at a relatively backward level in China. Southwest China needs to increase the interconnection level with other regions and the economic cooperation opportunities with the neighboring countries, so as to promote the transformation and upgrading of logistics industry and economic growth. (2) Pay attention to transportation development. Since most cities in Southwest China are located in mountainous region, the development of cities depends to a large extent on convenient transportation. Inconvenient transportation will increase the economic cost of communication with other cities. Thus, improving the highway and railway network can provide strong support for the inter-city logistics enterprise connection and economic exchange, and achieve the radiation-driven development of core cities. (3) Enhance government differentiated support. For poor and backward areas, decision makers should provide policy support and fund investment, such as formulating policies to attract high-quality talents, improving the living and business environment, and increasing the population agglomeration level, thereby promoting consumption and the economic growth. Therefore, it is necessary to formulate differentiated regional development strategies based on the different geographical conditions, traffic conditions, and public resource allocation of various provinces and cities. 


\subsection{Discussion}

As a participant in the New Western Land-Sea Corridor, Southwest China has an important strategic position in the regional development pattern. Therefore, it should seize development opportunities to achieve high-quality development of regional economy and logistics industry. In the context, we conducted this study on the evolution process of logistics industry and economy and the spatio-temporal distribution characteristics between them, which can provide references for the related researches. From 2011 to 2019, the development of logistics industry and economy in Southwest China has been confirmed in other studies [30, 31]. Research on the cooperation characteristics scientifically will also help government decision makers to formulate a scientific economic development pattern and a logistics industry development strategy based on different stages and location advantages, so as to achieve the coordinated progress between the two. The decision makers should pay attention to the perfection of logistics infrastructure and the efficient use of regional resources for cities of which the logistics industry development level is below the average. Furthermore, it needs to be realized that high-quality economic development cannot be achieved by logistics industry alone. Cities need to attach importance to the common development of related industries, such as the tertiary industry while developing core industries. In the future, this research will take external environmental factors into consideration and explore how the development in surrounding cities or countries impact the cooperation between the logistics industry and the economy in local area.

Acknowledgements The authors would like to thank in advance the Editors-in-Chief, the Associate Editor, and the anonymous referees for their time and efforts to handle and review this paper.

Author Contributions NM: conceptualization, methodology, software, data curation, funding acquisition, writing — original draft, writingreview and editing. YW: funding acquisition, resources, methodology, software, supervision, writing - original draft, writing-review and editing. PT: investigation, validation, writing—review and editing.

Funding Not applicable.

Availability of Data and Materials The data that support the findings of this study are available on request from the corresponding author, [N. Y. Mu].

\section{Declarations}

Conflict of Interest The authors declare that they have no competing interests.

Ethics Approval and Consent to Participate Not applicable.

Consent for Publication Not applicable.
Open Access This article is licensed under a Creative Commons Attribution 4.0 International License, which permits use, sharing, adaptation, distribution and reproduction in any medium or format, as long as you give appropriate credit to the original author(s) and the source, provide a link to the Creative Commons licence, and indicate if changes were made. The images or other third party material in this article are included in the article's Creative Commons licence, unless indicated otherwise in a credit line to the material. If material is not included in the article's Creative Commons licence and your intended use is not permitted by statutory regulation or exceeds the permitted use, you will need to obtain permission directly from the copyright holder. To view a copy of this licence, visit http://creativecommons.org/licenses/by/4.0/.

\section{References}

1. Liu, X.: 70 years of logistics in China: striving ahead and Spanning development. China Econ. Trade Guide 18, 34-36 (2019)

2. Jing, N., Cai, W.: Analysis on the spatial distribution of logistics industry in the developed East Coast Area in China. Ann. Reg. Sci. 45(2), 331-350 (2010)

3. Yao, X., Cheng, Y., Zhou, L., Song, M.: Green efficiency performance analysis of the logistics industry in China: based on a kind of machine learning methods. Ann. Oper. Res. 308, 727-752 (2022)

4. Jiang, W.H., Xu, L., Chen, Z.S., Govindan, K., Chin, K.S.: Financing equilibrium in a capital constrained supply Chain: the impact of credit rating. Transp. Res. Part E Logist. Transp. Rev. 157, 102559 (2022)

5. Chen, P.: Research on the status quo and countermeasures of China's maritime logistics development in the new period. J. Coast. Res. 98(sp1), 207 (2019)

6. Zhang, W.: Economic geography and transportation conditions with endogenous time distribution amongst work, travel, and leisure. J. Transp. Geogr. 15(6), 476 (2007)

7. Sainz, R., Baños, J., Val, S., Kattour, S.: The economic impact of logistics infrastructure: the case of PLAZA - the Zaragoza Logistics Platform. Transp. Plan. Technol. 36(4), 299 (2013)

8. Lean, H., Huang, W., Hong, J.: Logistics and economic development: experience from China. Transp. Policy 32, 96-104 (2014)

9. Jie, S.: Relations and suggestions for the joint development of regional logistics and regional economy. Bus. Econ. Res. 04, 87-89 (2018)

10. Gu, S., Zhou, Y.: The interactive study of regional logistics and economic development in Guangxi based on grey correlation analysis. Pract. Underst. Math. 49(02), 35-42 (2019)

11. Sun, M.: Analysis of the co-existence relationship between logistics industry agglomeration and regional economy in China-based on nonlinear perspective. Bus. Econ. Res. 01, 102-105 (2021)

12. Hu, B.: Study on the coupling degree of regional logistics and regional economy in Hunan province (master's thesis). Available from CNKI database (2017)

13. Huang, L., Xi, Y.: Discussion on the coordinated development of logistics industry and regional economy in the central region under the background of supply-side reform-take Jiangxi as an example. Bus. Econ. Res. 03, 143-145 (2019)

14. Xie, D., Zhang, Y.: Measurement research of integration development of regional logistics and regional economy in Beijing, Tianjin and Hebei. Pract. Underst. Math. 51(15), 123-132 (2021)

15. Haseeb, M., Mihardjo, L.W., Gill, A.R., Jermsittiparsert, K.: Economic impact of artificial intelligence: new look for the macroeconomic assessment in Asia-Pacific region. Int. J. Comput. Intell. Syst. 12(2), 1295-1310 (2019) 
16. Rodríguez, R.M., Labella, A., Martínez, L.: An overview on fuzzy modelling of complex linguistic preferences in decision making. Int. J. Comput. Intell. Syst. 9(sup1), 81-94 (2016)

17. Chen, Z.S., Zhang, X., Rodríguez, R.M., Pedrycz, W., Martínez, L.: Expertise-based bid evaluation for construction-contractor selection with generalized comparative linguistic ELECTRE III. Autom. Construct. 125, 103578 (2021)

18. Xiao, L., Chen, Z.S., Zhang, X., Chang, J.P., Pedrycz, W., Chin, K.S.: Bid evaluation for major construction projects under largescale group decision-making environment and characterized expertise levels. Int. J. Comput. Intell. Syst. 13(1), 1227-1242 (2020)

19. Chen, Z., Chen, J., Du, J.: The coupling and coordinated development of China's logistics industry and the national economy-empirical analysis based on inter-provincial panel data. China's Circ.Econ. 34(01), 9-20 (2020)

20. Yan, D., Yang, J., Gao, J.: Study on the unbalanced pattern and influencing factors between population and economy in the Yangtze River Delta. Geogr. Sci. 38(03), 376-384 (2018)

21. Xia, Y., Wang, G.Y., Zhang, X., Kim, G.B., Bae, H.Y.: Spatiotemporal similarity measure for network constrained trajectory data. Int. J. Comput. Intell. Syst. 4(5), 1070-1079 (2011)

22. Chen, Z.S., Yang, L.L., Rodríguez, R.M., Xiong, S.H., Chin, K.S., Martínez, L.: Power-average-operator-based hybrid multiattribute online product recommendation model for consumer decisionmaking. Int. J. Intell. Syst. 36(6), 2572-2617 (2021)

23. Shobugawa, Y., Wiafe, S., Saito, R., Suzuki, T., Inaida, S., Taniguchi, K., Suzuki, H.: Novel measurement of spreading pattern of influenza epidemic by using weighted standard distance method: Retrospective spatial statistical study of influenza, Japan, 19992009. BioMed Central 11(1), 20 (2012)
24. Yan, D., Sun, W., Sun, X.: Study on the evolution and drivers of population temporal and spatial patterns in the Yangtze River Delta. Geogr. Sci. 40(08), 1285-1292 (2020)

25. Wang, D., Li, X.: Coordinated study on population and economic development in the Wujiang Basin, Guizhou. Geogr. Sci. 39(03), 477-486 (2019)

26. Liu, B.: The National Development and Reform Commission held a press conference to introduce the promotion of high-quality construction of new land and sea routes in the west. China Econ. Soc. Dev. 17, 42-53 (2017)

27. Xie, X., Gong, X.: Analysis of China-India capacity cooperation in the context of "the Belt and Road." South Asia Study 04, 112-153 (2018)

28. Li, R.: Research on the driving role of the core cities of the metropolitan area (master's thesis). Cap. Univ. Econ. Trade. (2019). https://doi.org/10.27338/d.cnki.gsjmu.2019.000229

29. Shao, J., Hu, S., Wei, X., Tang, G.: Preliminary study on the traffic development pattern of the New Western Land-Sea Corridor. Highway 66(09), 318-322 (2021)

30. Wang, G., Zhang, H., Jin, T.: Driving force for China's economic quality development: structural adjustment or technological progress. Economist 06, 59-67 (2020)

31. Lun, J.: Comprehensive evaluation research of the development level of logistics industry in 31 provinces and cities in China. Invest. Entrep. 32(02), 50-52 (2021)

Publisher's Note Springer Nature remains neutral with regard to jurisdictional claims in published maps and institutional affiliations. 